\title{
Research on the Integrated Development Strategy of Railway Tourism in Sichuan Province Considering the Accessibility of High-speed Rail and Tourist Attraction
}

\author{
LI Li ${ }^{1,2, *}$, ZHANG Mengying ${ }^{1}$, SHEN Xin ${ }^{1}$, WANG Xiaohong ${ }^{3}$ and WANG Liang ${ }^{4}$ \\ ${ }^{1}$ School of Transportation and Logistics, Southwest Jiaotong University, Chengdu 610031, Sichuan, China \\ ${ }^{2}$ National United Engineering Laboratory of Integrated and Intelligent Transportation, Chengdu 610031, Sichuan, China \\ ${ }^{3}$ Guiyangnan Railway Station, China Railway Chengdu Group Co.,Ltd., Guiyang 550005, Guizhou,China \\ ${ }^{4}$ Safety Inspection Unit, China Railway Chengdu Group Co.,Ltd., Chengdu 610082, Sichuan, China
}

\begin{abstract}
In response to targeted poverty alleviation, traffic + tourism and other national strategies, exploring the integration development direction of High-speed Railway and tourism in Sichuan Province, this article combed the railway tourism basic conditions of Sichuan Province, used mathematical statistics and kernel density estimation to study the spatial distribution of tourist resources and High-speed Railway. Based on urban nodes, the minimum travel time between nodes, the urban power, tourism resources and other elements, constructed travel accessibility time measurement model and attractive model, and used ArcGIS to compute the accessibility value of High-speed Railway and the coefficient of tourist attraction. Finally, for the regions with different tourism resource quality and the accessibility of High-speed Rail in Sichuan, based on the calculation results, the problem of rail tourism and the national policy, the High-speed Railway tourism plans and development strategies are proposed respectively.
\end{abstract}

\section{Introduction}

Sichuan Province is the focus of many important strategies, such as the Belt and Road, China Western Development, integrated development of transport and tourism, and targeted poverty alleviation. Sichuan Province is rich in tourism resources, but due to the relatively backward development of transportation, the distribution of tourism activities is extremely uneven. It is of great significance to discuss how to organically integrate tourism attractions with High-speed Railway, carry out tourism activities and drive regional economic development.

Some scholars proposed to promote the integrated development of High-speed Railway and tourism according to the current situation of railway tourism in China [1]. Many studies have put forward suggestions for the development of railway tourism from the aspects of policy planning [2], product design [3], Railway heritage tourism [4], marketing organization [5], etc. However, due to the lack of in-depth consideration of the relationship between railway and tourism, the market response is weak. In the relevant studies which consider the relationship between High-speed Railway and tourism, High-speed Rail is mostly used as a means of transportation for tourism [6], or tourism development countermeasures are proposed by analysing the evolution of tourism spatial structure under the influence of High-speed Railway [7-9].

There is a lack of articles on railway tourism product design and strategy research based on accessibility and tourist attraction analysis. So this article is based on the spatial distribution of High-speed Railway and tourism resources in Sichuan Province, using related information data of the High-speed Rail network and various tourist attractions to compute the measurement value of accessibility and build tourism attraction model, using ArcGIS analysis the High-speed Railway accessibility and the tourism attraction of the cities in Sichuan Province, so that can provide advice for railway planning and railway tourism resources' development of Sichuan Province and provide means for targeted poverty alleviation, boost the integration of High-speed Railway and tourism.

\section{Status analysis of railway tourism in Sichuan Province}

\subsection{Distribution of Sichuan High-speed Railway network}

Chengdu is the radiated centre of the High-speed Railway network in Sichuan Province, and the radiation range is mainly in some areas of eastern Sichuan, the information of Sichuan High-speed Railway is shown in Table 1.

\footnotetext{
*Corresponding author: speciallili@swjtu.edu.cn
} 
Table 1. Sichuan High-speed Railway Information

\begin{tabular}{|c|c|c|c|}
\hline $\begin{array}{c}\text { High-speed } \\
\text { Railway Line }\end{array}$ & $\begin{array}{c}\text { Design } \\
\text { speed } \\
/\left(\mathrm{km} \cdot \mathrm{h}^{-1}\right)\end{array}$ & $\begin{array}{c}\text { Total length } \\
/ \mathrm{km}\end{array}$ & $\begin{array}{c}\text { Number of } \\
\text { stations }\end{array}$ \\
\hline $\begin{array}{c}\text { Xi'an- } \\
\text { Chengdu }\end{array}$ & 250 & 317 & 17 \\
\hline $\begin{array}{c}\text { Chengdu- } \\
\text { Guiyang }\end{array}$ & 250 & 389 & 24 \\
\hline $\begin{array}{c}\text { Chengdu- } \\
\text { Dujiangyan }\end{array}$ & 160 & 94.2 & 12 \\
\hline $\begin{array}{c}\text { Chengdu- } \\
\text { Ya'an }\end{array}$ & $160-200$ & 140 & 11 \\
\hline $\begin{array}{c}\text { Chengdu- } \\
\text { Chongqing }\end{array}$ & 250 & 185.5 & 11 \\
\hline $\begin{array}{c}\text { Chengdu- } \\
\text { Suining- } \\
\text { Chongqing }\end{array}$ & 200 & 146 & 18 \\
\hline
\end{tabular}

\subsection{Spatial structure analysis of Sichuan tourism resources}

China National Tourism Administration rated tourism resources into five categories In this article, various Alevel tourism resources in Sichuan Province are analysed by kernel density method. The results are shown in Figure 1 .

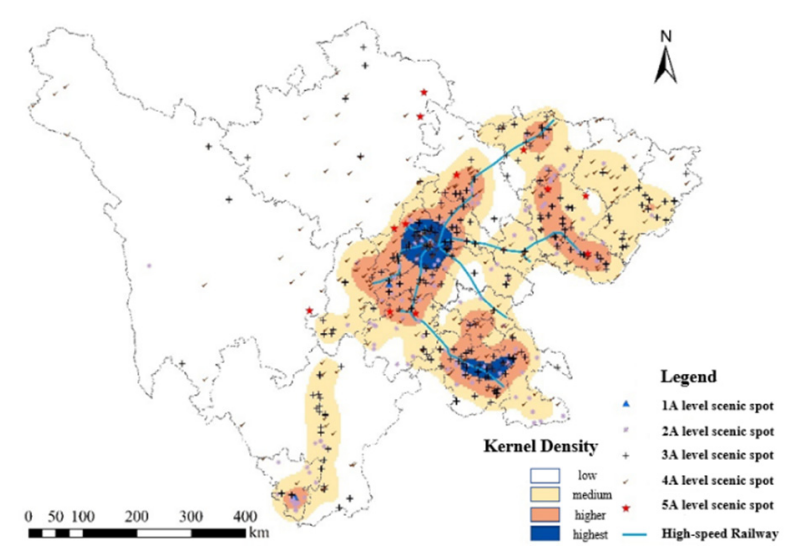

Fig.1.Distribution and kernel density of tourist spots in Sichuan Province

There are 613 class A tourist spots in Sichuan Province. Among them, there are 12 class 5A tourist spots, mainly located in Tibetan Qiang Autonomous Prefecture of Ngawa, Leshan and other places. There are 260 class 4A tourist spots, mainly distributed in Chengdu, Ya'an, Bazhong and other places. There are 213 class 3A tourist spots, mainly distributed in Chengdu, Yibin and other places. The number of high-quality spots above $3 \mathrm{~A}$ accounts for up to $79.12 \%$. The statistical analysis of the quantity of tourism resources in each city of Sichuan shows that, the number of class A tourist spots in Chengdu account for $14.85 \%$ of Sichuan's total spots, ranking the first in the province. Ziyang, which has the least spots, only accounts for $1.47 \%$. It can be seen that A-level and high quality spots in Sichuan Province are rich, but they are not evenly distributed.
Kernel density analysis can more clearly identify the distribution density of tourism resources. Sichuan province's tourist spots are mainly located in the central and eastern regions, which are covered by a number of High-speed Railway lines and abundant in tourism resources. Although the density of spots in the northern region is extremely low, there are many high-quality spots, such as Huanglong scenic Spot, Jiuzhaigou scenic Spot and so on. In the southern region, there are also many spots along Panzhihua area, which are distributed in zonation, but the overall traffic conditions are relatively weak.

\section{Analysis on the accessibility of High- speed Railway and tourist attraction in Sichuan}

\subsection{Calculation of accessibility value}

The difficulty for tourists to reach the destination by Highspeed Rail or interchange to other vehicles can reflect the regional accessibility level. The easier it is for tourists to reach the destination, the lower the traffic resistance and the higher the accessibility level. In this paper, the travel time between nodes is used to represent traffic impedance to measure the accessibility. The smaller the impedance, the smaller the accessibility measurement and the higher the accessibility level.

The accessibility measurement model is as equation(1):

$$
D_{i}=\frac{\sum_{j=1}^{d} T_{i j}}{d}
$$

Where $T_{i j}$ represents the minimum time for node $i$ to reach node $j$ through the traffic network, $d$ represents total number of selected nodes, the value is 21 , $D_{i}$ represents the accessibility measurement for node $i$.

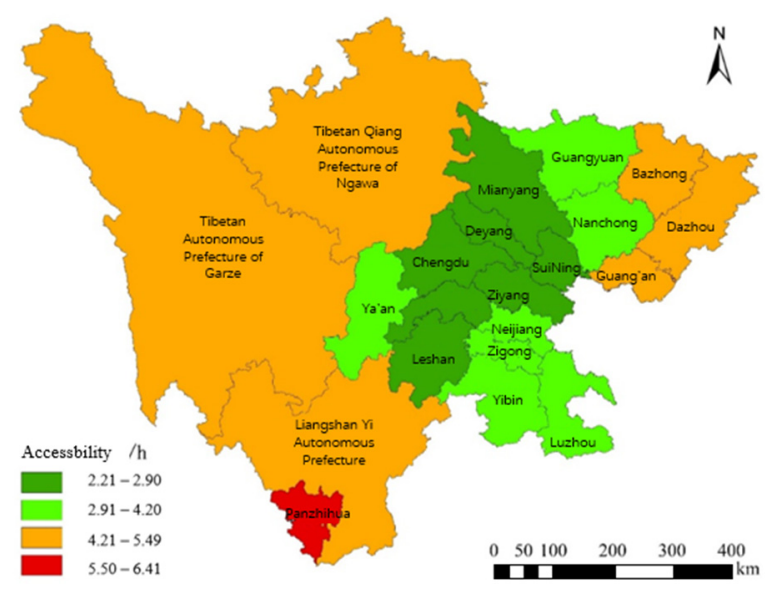

Fig.2.Comparison of urban accessibility in Sichuan Province without High-speed Rail 


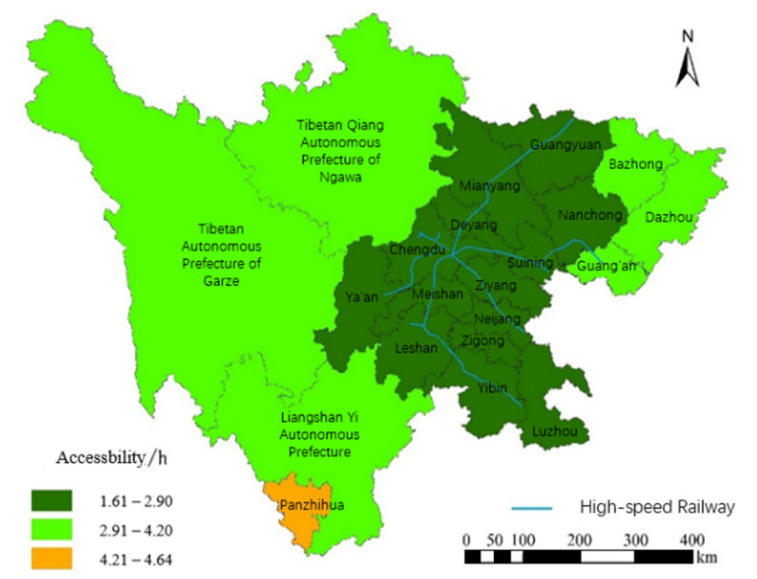

Fig.3.Comparison of urban accessibility in Sichuan Province with High-speed Rail

From Fig.2 and Fig.3, the operation of High-speed Rail has increased urban's accessibility level in Sichuan Province significantly, and strengthened the Chengdu's core position of tourism. Compared the change in the accessibility measurements, we can find that the increase of Guang'an, Tibetan Autonomous Prefecture of Garze, Liangshan Yi Autonomous Prefecture and other peripheral is more significant than Chengdu and other core areas, which indicates the High-speed Rail has bigger influence on the accessibility level to underdeveloped area. Chengdu has the highest accessibility level, while Panzhihua has the lowest. The gap between their accessibility measurements has reduced from 4.20 to 3.03, indicating that High-speed Rail has improved the unbalanced traffic level in Sichuan Province.

It can be seen from Figure 3, with Chengdu as the center, the accessibility level gradually attenuates to the outer circle. The central and eastern regions of Sichuan, such as Chengdu, Deyang, Leshan and Meishan, are in the first echelon with the highest accessibility level. Although there is no High-speed Railway in Tibetan Qiang Autonomous Prefecture of Ngawa, Tibetan Autonomous Prefecture of Garze, Liangshan Yi Autonomous Prefecture etc., the accessibility has also been improved due to the continuous improvement of the entire road network, while Panzhihua area is still a weak area of traffic.

\subsection{Calculation of tourist attraction coefficient}

Tourist attraction is an important factor to attract tourists to travel. In a narrow sense, it refers to the attraction of tourism resources. In a broad sense, it is related to the convenience degree and cost of the transportation. It can affect the choice of tourists and the spatial distribution of regional tourism, so it is an important evaluation index in the process of tourism planning and development.

This article modifies the gravity model from the perspective of time accessibility, the revised formula is shown in equation(2)-(3), taking $t_{i j}$ in the accessibility measurement model as the cost of the gravity model. The modified gravity model is shown as:

$$
\begin{aligned}
& L_{i j}=\frac{P_{i} \cdot A_{j}}{t_{i j}} \\
& L_{j}=\sum_{i=1}^{n} L_{i j}
\end{aligned}
$$

Where $L_{i j}$ represents the tourist attraction of destination $j$ to tourist source $i . L_{j}$ represents the total attractions of destination $j$ to other cities along the Highspeed Rail line. $P_{i}$ represents the economic strength of the tourist source $i$ is calculated by the sum of the numerical weight of the GDP and the total resident population of the city. $A_{j}$ represents destination attraction is calculated by the sum of the numerical weight of tourism resource attraction, GDP and total resident population of the city. $t_{i j}$ represents the shortest time it takes to travel from source $i$ to destination $j$.GDP and urban resident population are derived from the 2019 statistical bulletins of National Bureau of Statistics. The shortest time between cities is obtained by consulting the system of 12306 China Railway.

In this article, the Cleveland's dot plots which can emphasize the ranking and gap of data is used to show the attraction coefficient of cities along the line with or without High-speed Rail. In Figure 4, hollow circles and solid circles are respectively used to represent the cases without High-speed Rail and with High-speed Rail. At the same time, the attraction growth multiple brought by High-speed Rail are described by the size of the circle. The larger the circle is, the greater the growth multiple is, and the growth multiple is marked at the end of the axis of the city. Selected several cities with higher growth multiples, as shown in Fig.4.

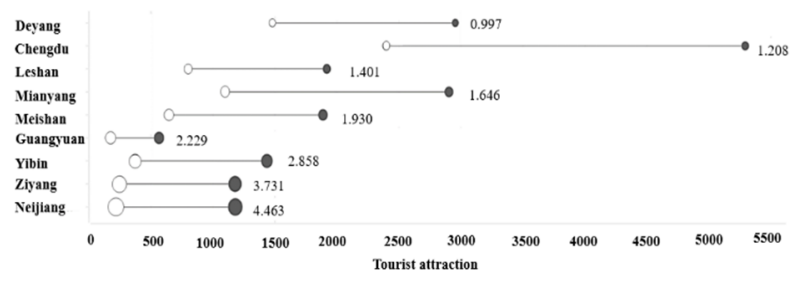

Fig.4. Tourism attraction coefficient and growth multiple of cities with or without High-speed Rail in Sichuan Province

From fig.4, driven by Chengdu-Guiyang Railway, Chengdu-Chongqing High-speed Railway, Xi'anChengdu High-speed Railway and other High-speed Rail lines, the average amount of increase of tourism attraction of cities along the line is more than $200 \%$, of which Neijiang has the highest increase. According to the previous analysis, Neijiang has few tourism resources, and the proportion of high-quality spots is not high, so it can be inferred that inconvenient transportation might be an important reason for restricting the tourism development in Neijiang. Both Deyang and Neijiang are lack of tourism resources, and no matter with or without High-speed Rail, the accessibility level of Deyang is higher than Neijiang, but the attraction growth of Deyang is at the bottom of cities along the route, which is related to Deyang mainly developments industrial manufacturing and lacks of 
competitiveness of tourism resources.

The amount of increase of tourist attraction in $\mathrm{Yi}$ bin and Leshan are also at the forefront. Because of rich cultural heritage, plenty of scenic spots and sp ecialties, their comprehensive attraction is much high er than that of other cities in Sichuan. The improve ment of accessibility makes it more compact with th e central city and makes tourism resources more attr active.

\section{Problems and Strategies for the Integrated Development of Railway Tourism in Sichuan Province}

Although supported by national policies, there are still some problems and bottlenecks in the development of railway tourism. First, in terms of marketing, the planning, packaging, publicity, and Internet construction of railway tourism products are still lacking. Second, in terms of human resource development, there is a lack of compound talents with dual knowledge backgrounds in railway transportation and tourism. Third, in terms of the management mechanism, the railway authorities have not been able to effectively support the railway tourism products. Due to lack of top-down design, railway tourism products cannot deeply rely on and use the internal resources of the railway. The impact of new technologies such as smart tourism and digital transportation has caused the competitiveness of tourism market to increase.

Based on the development status, the level of resource quality and accessibility in various regions of Sichuan, specific measures for the integrated development of "Railway + Tourism" in Sichuan Province are proposed from the following different perspectives.

(1) High accessibility and high quality resources:

Areas with outstanding tourism resources and high transportation accessibility generally have strong comprehensive strength and high tourist attraction, such as Chengdu, Leshan,Meishan and other places. In such areas, it is necessary to appropriately increase the frequency of trains during holidays, plan to operate crossprovincial and cross-city tourism trains, and the connection problems should be paid attention, for example, promote "High-speed Rail + Shared Cars". Comprehensive consideration of regional economic development and modern tourism, in the context of "MaaS", create a mobile terminal-based service system, digitally share tourism transportation, and develop "Smart Tourism".

(2) High accessibility and low quality resources:

In areas with disadvantaged tourism resources and relatively high traffic accessibility, in order to avoid the homogenization of tourism resources, there is an urgent need to create a leading market segment in the tourism industry and launch special tourism projects to attract tourists. Improve from the perspective of railways, use railway resources to create products, and operate special themed trains, such as the "Panda Train". From the perspective of scenic spots, we encourage industry, agriculture and other industries to carry out cross-field collaborative development towards tourism. For example,
Deyang, Mianyang and other places can use abandoned factories and production base to develop tourism parks.

(3) Low accessibility and high quality resources:

For areas with high-quality tourism resources but low traffic accessibility, it is necessary to strengthen the construction of transportation infrastructure, clarify resource advantages, and select stations' position according to actual conditions. For example, Tibetan Qiang Autonomous Prefecture of Ngawa and Panzhihua have unique and spectacular scenery, but the geographical span between scenic spots is too large, and the planned introduction of railway lines will greatly promote the development of such areas. In addition, these areas are rich in product resources, should actively respond to the targeted poverty alleviation policy and run the poverty alleviation train through the mode of "railway + tourism + poverty alleviation".

For the scattered high-quality resources along the railway, a special circular-route tourism train is opened. Under the policy background of cultural and tourism integration, creative tourism, combined with local tourism resources, set the local cultural as the background of railway tourism products. For example, Guangyuan, Guang'an and other places can create red tourism. Given the specific cultural theme of the tourist train, the design of the interior and appearance of the station incorporates local culture.

\section{Acknowledgements}

This study was supported by the Soft Science Research Program of Science and Technology Department of Sichuan Province: The integrated development strategy combining railway and tourism in China's Western Region (No. Q113620S01018)

\section{References}

1. G. Yang, J. Liang, Y. Luo, L. Lei, M. Ren, Railway Economics Research, 01, 28-34 (2019)

2. Y. Zhang, China Construction, 08, 130-131 (2019)

3. B. Liu, Railway Transport and Economy, 06, 90-94 (2016)

4. H. Wang, Railway Transport and Economy, 06, 65-69 (2017)

5. S. Hu, J. Zeng, Y. Qian, X. Gang, Railway Transport and Economy, 08, 50-54 (2018)

6. L. Gong, Q. Yu, Tourism Forum, 3, 330-334 (2010)

7. D. Wang, T. Chen, L. Lu, L. Wang, Acta Geographica Sinica, 002, 214-233 (2015)

8. G. Zhang, X. Gao, Journal of Fujian Agriculture and Forestry University (Philosophy and Social Sciences), 02, 60-64 (2016)

9. H. Zong, Y. Huang, Human Geography, 03, 99$107+127$ (2019) 